\title{
A Study of Efficient Power Consumption Wireless Communication Techniques/ Modules for Internet of Things (IoT) Applications
}

\author{
Mahmoud Shuker Mahmoud, Auday A. H. Mohamad \\ Computer Technology Engineering Department, Al-Mansour University College, Baghdad, Iraq \\ Email: dr.m.s.mahmoud@muc.edu.iq, auday_abdulhussein@muc.edu.iq
}

Received 16 March 2016; accepted 19 April 2016; published 22 April 2016

Copyright (C) 2016 by authors and Scientific Research Publishing Inc.

This work is licensed under the Creative Commons Attribution International License (CC BY). http://creativecommons.org/licenses/by/4.0/

(c) (i) Open Access

\begin{abstract}
A study of wireless technologies for IoT applications in terms of power consumption has been presented in this paper. The study focuses on the importance of using low power wireless techniques and modules in IoT applications by introducing a comparative between different low power wireless communication techniques such as ZigBee, Low Power Wi-Fi, 6LowPAN, LPWA and their modules to conserve power and longing the life for the IoT network sensors. The approach of the study is in term of protocol used and the particular module that achieve that protocol. The candidate protocols are classified according to the range of connectivity between sensor nodes. For short ranges connectivity the candidate protocols are ZigBee, 6LoWPAN and low power Wi-Fi. For long connectivity the candidate is LoRaWAN protocol. The results of the study demonstrate that the choice of module for each protocol plays a vital role in battery life due to the difference of power consumption for each module/protocol. So, the evaluation of protocols with each other depends on the module used.
\end{abstract}

\section{Keywords}

IoT, Wireless Sensor Networks, Low Power Wireless Protocols, Wireless Low Power Consumption Modules

\section{Introduction}

A dramatic change towards a universal connection between every things and processing will lead to a third in-

How to cite this paper: Mahmoud, M.S. and Mohamad, A.A.H. (2016) A Study of Efficient Power Consumption Wireless Communication Techniques/Modules for Internet of Things (IoT) Applications. Advances in Internet of Things, 6, 19-29. 
dustrial revolution named Internet of Things (IoT). This revolution collects several sciences and technologies with each other, such as, Data Acquisition, Power Consumption, Wireless Sensor Networks, Radio and Mobile Communications, Data Analytic and Processing, Internet Technology. IoT takes its name from its wide spread applications from wearable fitness trackers to connected cars, spanning the industries of utilities, transportation, healthcare, consumer electronics, and many others.

The traditional use of the Internet has become inadequate to meet the industrial and civil requirements. The IoT is the candidate object to add new technologies to internet technology by enabling communications with and among smart objects, thus leading to the vision of "anytime, anywhere, any media, anything" communications. To this purpose, the IoT should be considered as part of the overall Internet of the future, which is likely to be dramatically different from the Internet use today [1].

A prediction of future connected devices over internet is shown in Figure 1 [2]. The graph shows a growth of devices such as phones, tablets, laptops, game consoles. The real large growth is predicted from all other types of connected small devices in areas like home automation, smart energy, elderly care at home, transportation, asset tracking and many others which will be a real candidate to be IoT devices.

So, IoT is a system based on billion smart sensors and actuators and to build such a system, new ideas about intelligent sensors and data computations and processing must be introduced. However, the first question must be introduced, that is how these sensors and actuators are interconnect, Ethernet cabling look like not a good idea. Indeed, only wireless offers the flexibility, scalability and cost efficiency needed to ensure viable uptake of the Internet of Things. The radio frequency wireless communication with its multitude and existing infrastructure offers a best solution for data traffic in IoT systems [3].

A limited power supply problem comes up with a wireless connectivity between sensors. Ideally, a system where a sensor can run on a single AAA battery for years is preferred in IoT applications. The solution which solves the issue of limited power supply is the IEEE 802.15.4 standard [4]. IEEE 802.15.4 standard specifies a wireless link for low-power personal area networks (LoWPANs). This standard is adopted by ZigBee Alliance to introduce ZigBee device which is a low cost, low power, wireless mesh networking standard targeted at wireless control and monitoring applications [5]. In general, when selecting a wireless technology for connected devices, a few considerations must be taken into account depending on the final application.

- Maximum throughput.

- Power consumption.

- Maximum distance range.

In this work, a study uses a comparative analysis for different techniques/modules which influence power consumption of a wireless communication system for IoT applications.

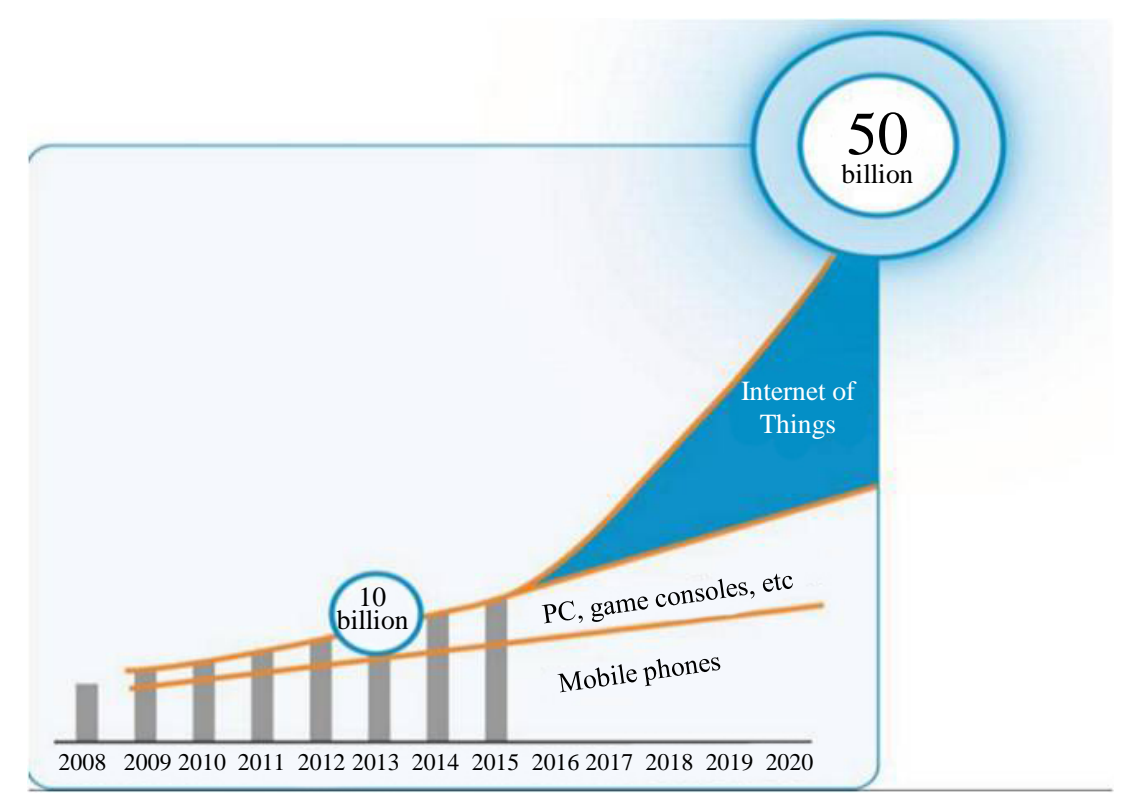

Figure 1. Device distribution in IoT [2]. 
The paper is arranged into five sections. Section 2 presents an overview of Internet of Things (IoT) fundamentals and its growth. Section 3 describes the wireless connectivity technology. Section 4 explains wireless sensor networks for IoT applications. This section is arranged into two subsections, first subsection describes the comparative between modules used for a certain short and long range wireless communication modules while the second subsection gives a comparison between different wireless protocols. Section 5 gives the conclusions that obtain from the study.

\section{IoT Fundamentals}

The Internet of Things (IoT) is a new paradigm that is increasing in popularity. It is defined as "an interconnection of uniquely identifiable embedded computing devices within the existing Internet infrastructure, offering advanced connectivity of devices, systems, and services that goes beyond machine-to-machine communications and covers a variety of protocols, domains, and applications" [6].

The word "Things" in IoT means the devices and objects from small one (like wrist watches and medical sensors) to really big ones (like robots, cars and buildings). It devices that interact with users by generating and retrieving information about and from their environment, they also contain hardware that allows them to control outputs (like relay, switches, and digital ports) as shown in Figure 2 [7].

IoT device constructed from four main components these are the Main Control Units (MCU-the brain of the devices), sensors that collect information-signals from the environment, the communication modules and the power sources [7].

In the future, all devices that benefit from an internet connection will be connected. In this Networked Society, every person and every industry will be empowered to reach their full potential. Internet of Things (IoT)

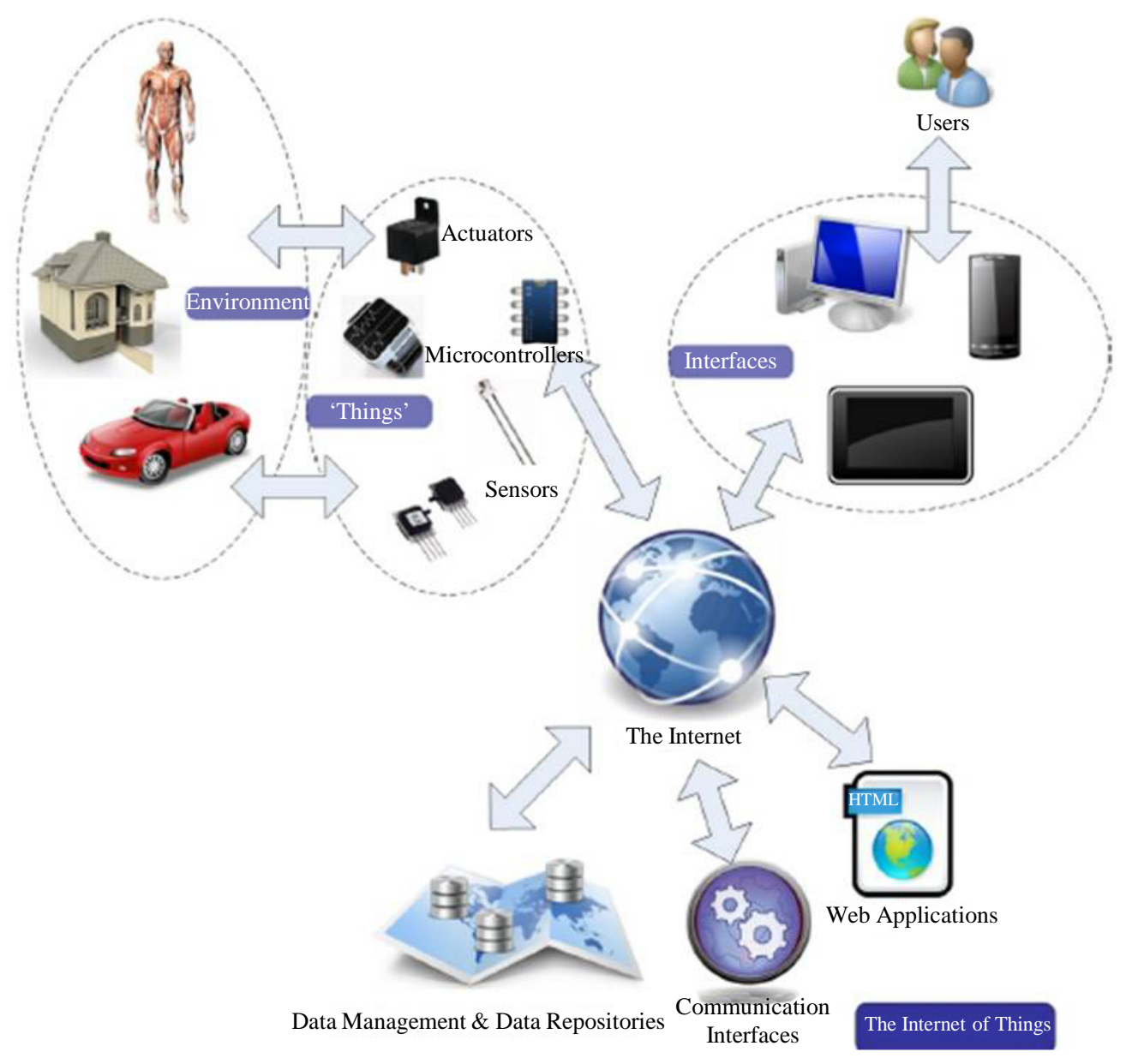

Figure 2. Illustration of internet of things. 
technology is a key enabler of this vision by delivering machine-to-machine (M2M) and machine-to-person communications on a massive scale.

Another prediction of growth for IoT applications can be seen in Figure 3 [8]. The prediction that there will be around 28 billion connected devices by 2021, of which more than 15 billion will be connected M2M and consumer-electronics devices. A large share of these will be applications served by short-range radio technologies such as Wi-Fi and Bluetooth, while a significant proportion will be enabled by wide area networks (WANs) that are primarily facilitated by cellular and low power wide area (LPWA) networks [8].

\section{Wireless IoT Connectivity Technologies}

There are different types of wireless technologies relevant for IoT; these technologies span different spaces from few centimeters to many kilometers. For short to medium range communication Wireless Personal and Local Area Network technologies (WPAN\LAN) such as: Bluetooth, ZigBee, 6LowPAN, and Wi-Fi are recommended. For long range communication the recommendation is for Wireless Wide Area Network technologies (WWAN) and these can be divided into two types whether to use licensed (Cellular 2G/3G/4G and 5G in future) or licensed-exempt technologies (LPWA LoRa, SIGFOX, and other). As depicted in Figure 4.

Connectivity is the foundation for IoT, and the type of access required will depend on the nature of the application. Many IoT devices will be served by radio technologies that operate on unlicensed spectrum and that are designed for short-range connectivity with limited QoS and security requirements typically applicable for a home or indoor environment.

\subsection{Short Range Connectivity Technologies}

Wi-Fi is a great candidate to ensure connectivity in IoT applications due to its tremendous growth over the past years, in spite of the much higher power consumption. Today, most places where there is something to send or some data to be transmitted, there's Wi-Fi coverage. Unfortunately, Wi-Fi has been out of reach for sensor communications due to the fairly large energy consumption with its traditional protocols.

Since 2006, this has changed when the Wi-Fi community started to apply a well-known technologies such as duty cycling, that is, putting chips in a sleep mode for most of the time and a low power Wi-Fi modules see lights such as Microchips RN171 module which is a standalone, embedded $802.11 \mathrm{~b} / \mathrm{g}$ Wireless Local Area Network (WLAN) module [9].

Another good candidate for short range connectivity is IEEE 802.15.4 technology. Several leading radio manufacturers have implemented IEEE 802.15.4. The Internet Engineering Task Force (IETF) introduced 6LowPAN protocol and ZigBee alliance produced ZigBee protocol over low power IEEE802.15.4 protocol. In particular the IETF 6LowPAN define the frame format and several mechanisms needed for the transmission of IPv6 packets on top of IEEE 802.15.4 networks. 6LowPAN is the acronym for IPv6 over low-power personal

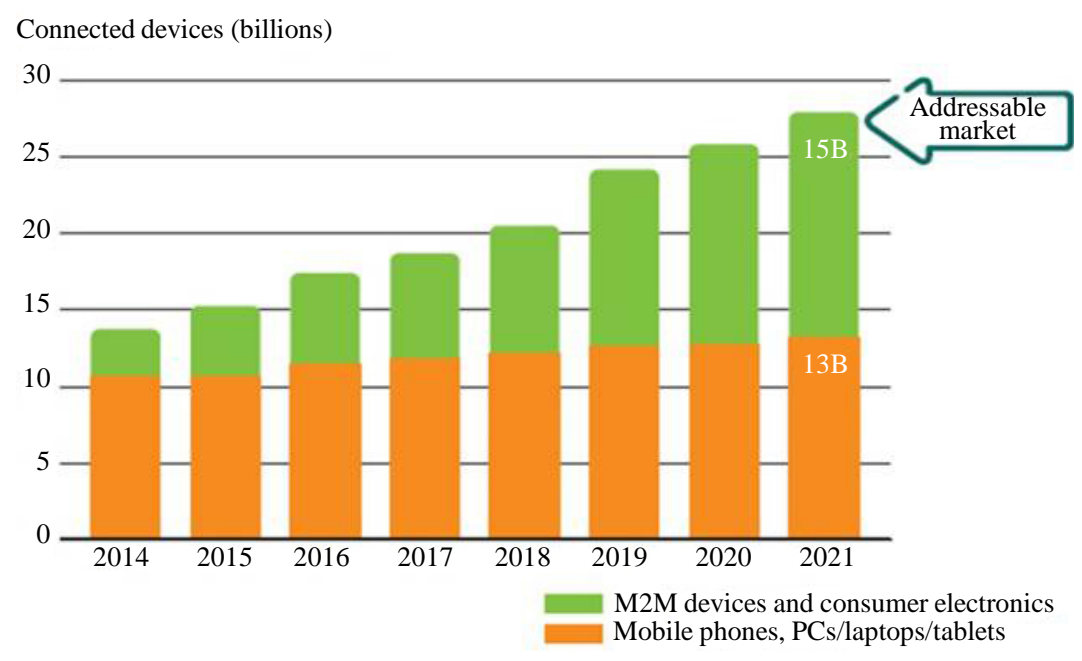

Figure 3. Growth in connected devices. 


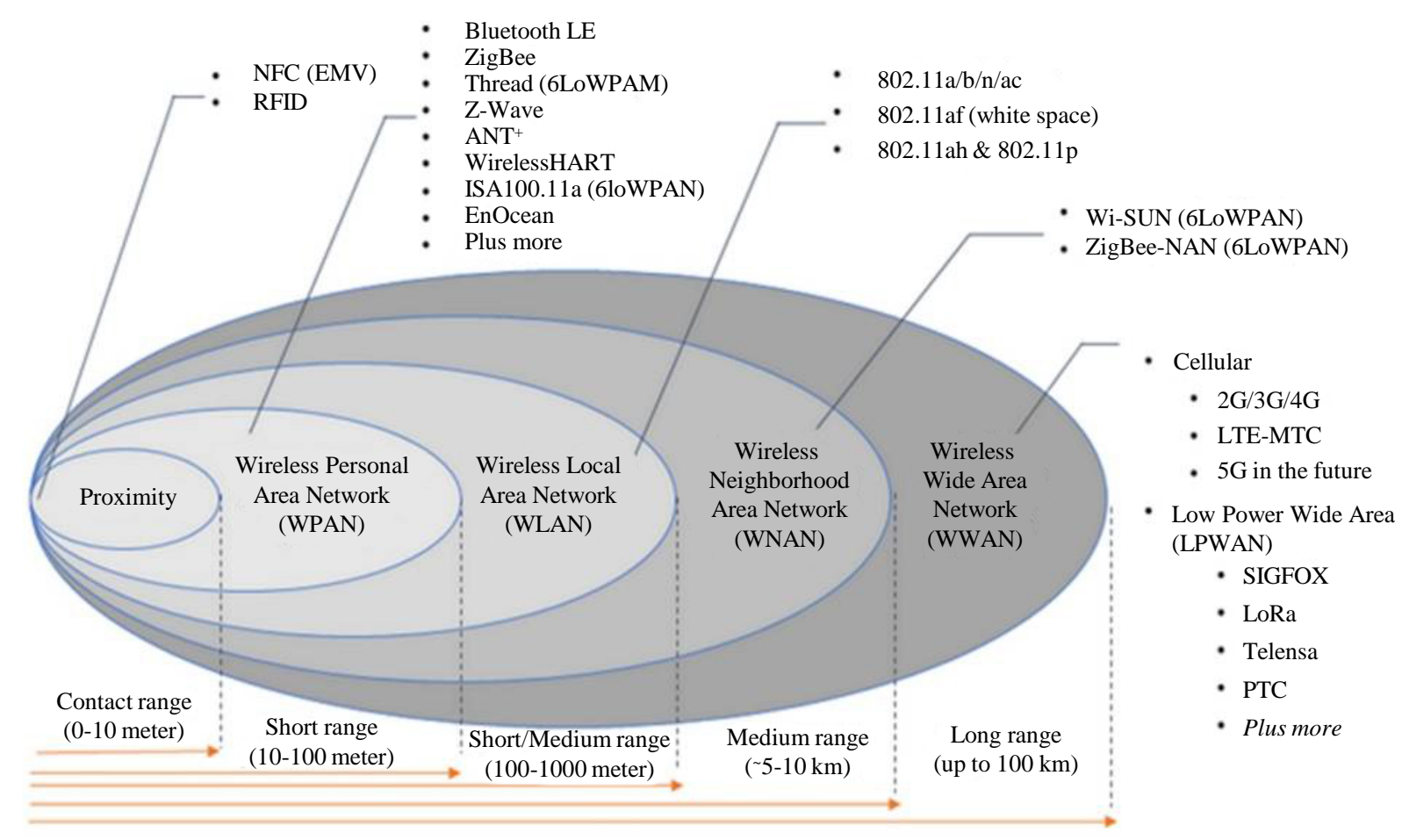

Figure 4. Wireless IoT connectivity technologies.

area networks. The concept behind 6LowPAN is to bring the Internet Protocol (IP) directly into small, low-cost sensor devices. Since there are not enough addresses in the IPv4, 6LowPAN starts from the premise of IPv6, with the aim of giving an address to every device [10].

Early optimization efforts show that Wi-Fi could be 10 times more energy efficient than ZigBee, in addition, given the wide spectrum of data rates required for IoT applications. IEEE has started working on the low power Wi-Fi version, which is standardized in IEEE 802.11ah.

\subsection{Long Range Connectivity Technologies}

Currently, there are two alternative connectivity tracks for the many IoT applications that depend on wide-area coverage:

\subsubsection{Cellular Technologies}

3GPP technologies like GSM, WCDMA, LTE and future 5G. These WANs operate on licensed spectrum and historically have primarily targeted high-quality mobile voice and data services. Now, however, they are being rapidly evolved with new functionality and the new radio access technology narrowband IoT (NB-IoT) specifically tailored to form an attractive solution for emerging low power wide area (LPWA) applications [8].

\subsubsection{Unlicensed LPWA}

new proprietary radio technologies, provided by, for example, SIGFOX and LoRa, have been developed and designed solely for machine-type communication (MTC) applications addressing the ultra-low-end sensor segment, with very limited demands on throughput, reliability or QoS. One way to segment IoT applications is to categorize them according to coverage needs and performance requirements (such as data speed or latency demands). Figure 5 [8], illustrates the different types of technologies that can be used for IoT with different coverage area and within the unlicensed spectrum in which this paper will focus.

Applications of cellular connectivity remain concentrated in traditional applications such as transportation, automotive, and location management. Cellular 2G connectivity provides the benefit of world-wide Nevertheless; there are limitations to cellular connectivity which LPWA addresses. These limitations fundamentally center on two key issues: high power consumption that does not allow battery operation over an extended period of 


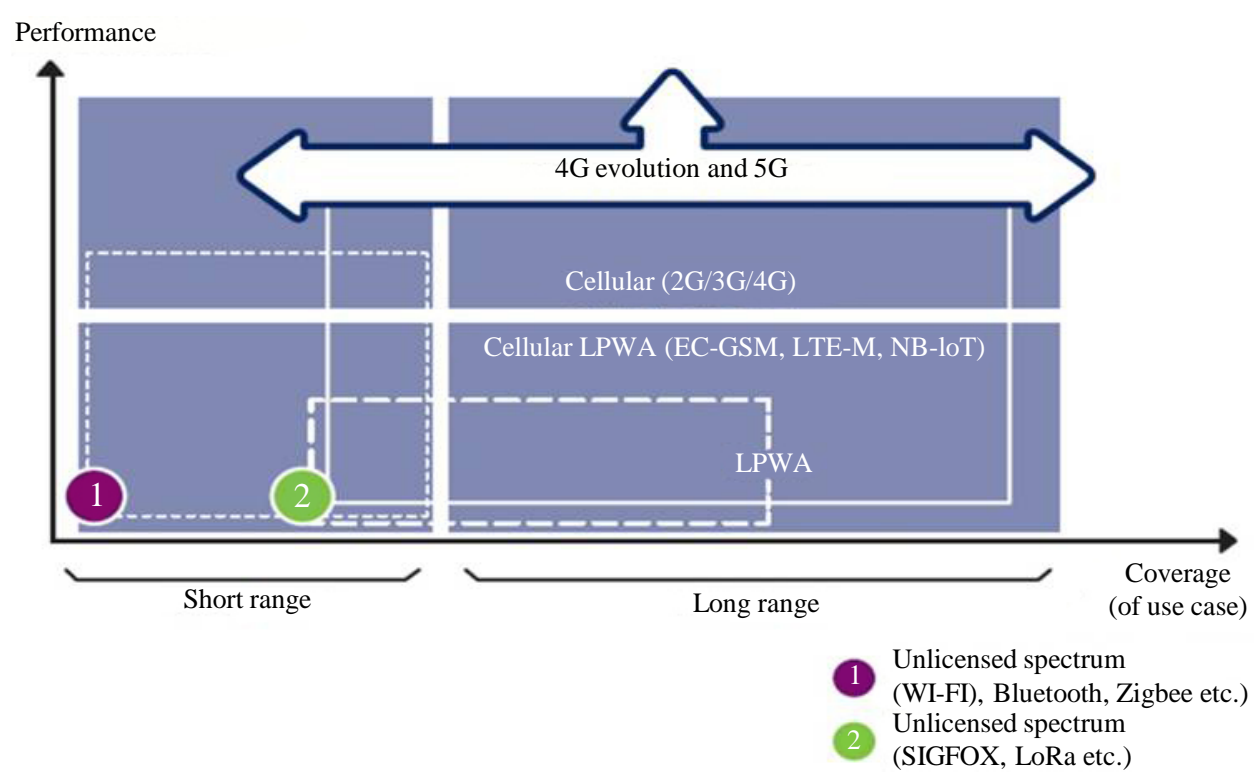

Figure 5. Technologies addressing different segments.

time reaching into the years, and the cost of service which includes the cost of the device and the supporting infrastructure that factors into the return on investment for the service provider.

In essence, LPWA technologies complement existing cellular mobile network and short range technologies, enabling wide area communications at lower cost points and better power consumption characteristics. As recently as early 2013, the term "LPWA" did not even exist. The fact that the LPWA space has since then become one of the fastest developing aspects of the Internet of Things (IoT) market is testimony to the incredible potential for LPWA technologies [11].

Low-Power Wide-Area (LPWA) is a generic term for a group of technologies with the following key characteristics:

- $\quad$ Long battery life, often in excess of 10 years.

- Wide area connectivity characteristics, allowing for out-of-the-box connected solutions.

- $\quad$ Low cost chipsets and networks.

- $\quad$ Limited data communications throughput capacity.

LPWA technologies are typically narrowband (with some exceptions) and operate in the ISM license-exempt spectrum bands. In recent months, GERAN and 3GPP standards organizations started on a process of standardizing narrowband technology for use in mobile spectrum. Several proponents of LPWA technologies have put forward their technologies. The competition in the standards race extends to 3GPP, where the roadmap for cost reduced LTE module for IoT applications is under development (LTE-M), and other standard organizations that are focusing on $5 \mathrm{G}$ technologies.

Market forecasts for LPWA vary between a low of 1 billion and a high of 3 billion connected devices by 2020, most of which in North America, Europe and the Asia Pacific region deployed in lead applications including smart cities, smart buildings, agriculture \& environment, and utilities [11] [12].

\section{Wireless Sensor Networks for IoT Applications}

Sensors in wireless sensor networks applications are grouped as clusters to inform nodes called sensor nodes. These nodes are typically powered by battery power supply. In IoT applications these nodes must do its function for years without change their batteries. So, the battery lifetime is the most important parameter in the design of sensor nodes for IoT applications. The battery life time in sensor nodes influence by [3]:

- Wireless Communication Protocol.

- $\quad$ Used module for a certain Wireless Communication Protocol.

- The coverage range and the distance between sensor nodes.

- $\quad$ The nature of application. 


\subsection{Used Module for a Certain Wireless Communication Protocol}

\subsubsection{Low Power Wi-Fi Modules for Short Range Connectivity}

The low-power Wi-Fi chip/module has an impact factor in reducing the power consumption of battery used in Wi-Fi sensors. Low-power Wi-Fi modules increase years of battery lifetime in same time they providing easy installation to existing Wi-Fi network without any extra gateway. New low-power Wi-Fi modules have been introduced in the markets that support IEEE 802.11 protocol. The famous available low power Wi-Fi chips/modules in markets today are G2M5477 module from G2 Microsystem, RN171 module from Microchip, QCA4004 module from Qualcomm, GS1011M from Gain Span, RS9110-N-11-02 Module from Red pine and RTX41x series Modules from RTX. A particular comparison between these modules in term of power consumption is illustrated in Table 1.

Figure 6 shows the consuming power in $(\mathrm{dBm})$ for each low power Wi-Fi Module. Obviously it's noted that RTX41x series consume less power compared to other modules if we ignore the effect of the of data size and rate values during transmission or receiving data. So we can candidate this module to compare low power Wi-Fi technique with other wireless communication techniques for IoT sensor networks.

\subsubsection{IEEE 802.15.4 RF Modules for ZigBee and 6LoWPAN for Short Range Connectivity}

ZigBee and 6LoWPAN protocols designed over IEEE 802.15.4 protocol for low power consumption applications such as low power wireless sensor networks. So, they are good candidates in IoT applications in term of low power consumption. The IEEE 802.15.4 modules are typically integrated with radios responsible for the wireless transmission, microcontrollers responsible for orchestrating and controlling the data flow in the chip, and memory responsible for storing the data.

IEEE 802.15.4 protocol allows a network designer to perform energy planning by setting the duty cycle of sensor nodes. ZigBee protocol define an operation which makes the ZigBee module operates at low power sleep mode for a long period of time, so it allow sensor nodes to stay in low power sleep states for most of the time. The 6LoWPAN protocol, on the other hand, is based on IPv6 and operates in a fully asynchronous way. It adopts a mesh topology and uses a routing algorithm which does not take care of the sleeping node thus requiring approaches such as low-power listening for energy saving purpose [18]. A particular comparison between different IEEE 802.15.4 modules in term of consuming power is in Table 2.

Table 1. Particular comparison for different low power Wi-Fi modules.

\begin{tabular}{cccccccc}
\hline Company & Module & IEEE Protocol & $\mathrm{V}_{\mathrm{DD}}($ Volt) & $\mathrm{I}_{\mathrm{TX}}(\mathrm{mA})$ & $\mathrm{I}_{\mathrm{Rx}}(\mathrm{mA})$ & $\mathrm{I}_{\text {sleep }}(\mu \mathrm{A})$ & Max. Bit Rate $(\mathrm{Mb} / \mathrm{S})$ \\
\hline Microchip [9] & RN171 & $802.11 \mathrm{~b} / \mathrm{g}$ & 3.3 & 190 & 40 & 4 & 54 \\
Qual Comm [13] & QCA4004 & $802.11 \mathrm{n}$ & 3.3 & 250 & 75 & 130 & 10 \\
Gain Span [14] & GS1011M & $802.11 \mathrm{~b}$ & 3.3 & 150 & 40 & 150 & 11 \\
G2 Microsystem [15] & G2M5477 & $802.11 \mathrm{~b} / \mathrm{g}$ & 3.3 & 212 & 37.8 & 4 & 11 \\
Redpine [16] & RS9110-N-11-02 & $802.11 \mathrm{~b} / \mathrm{g} / \mathrm{n}$ & 3.3 & 19 & 17 & 520 & 11 \\
RTX [17] & RTX41x Series & $802.11 \mathrm{~b} / \mathrm{g} / \mathrm{n}$ & 3.3 & 0.760 & 0.760 & 3 & 10 \\
\hline
\end{tabular}

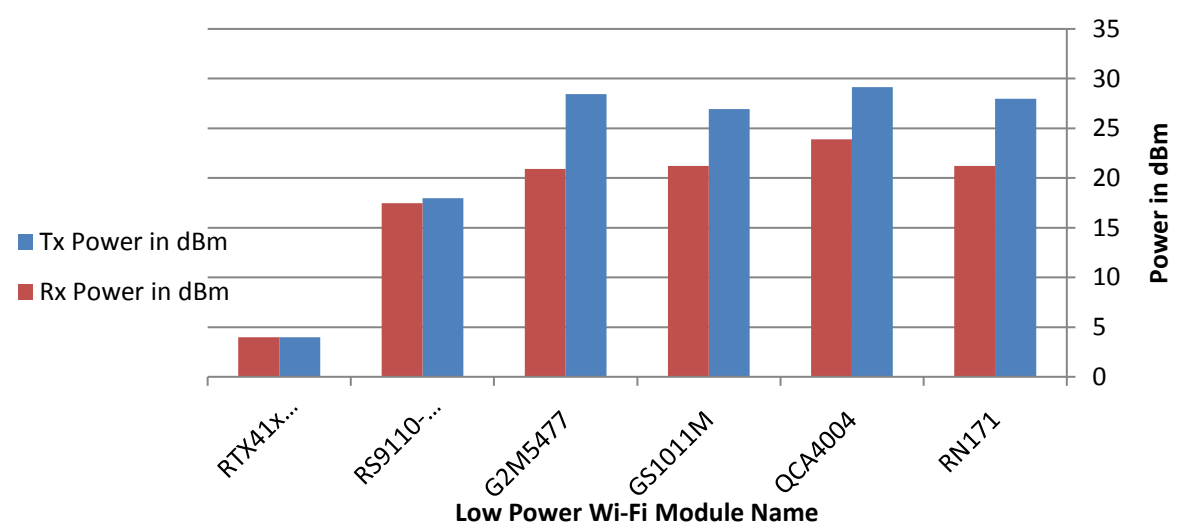

Figure 6. Power consumption in (dBm) for multiples low power Wi-Fi modules. 
Table 2. Particular comparison for different IEEE 802.15.4 modules.

\begin{tabular}{|c|c|c|c|c|c|c|c|c|}
\hline Company & Module & $\begin{array}{c}\text { IEEE } \\
\text { Protocol }\end{array}$ & $\begin{array}{c}\text { Designed for network } \\
\text { protocols }\end{array}$ & $\begin{array}{l}V_{\text {DD }} \\
\text { (Volt) }\end{array}$ & $\begin{array}{c}\mathbf{I}_{\mathrm{TX}} \\
(\mathbf{m A})\end{array}$ & $\begin{array}{c}\mathbf{I}_{\mathrm{Rx}} \\
(\mathrm{mA})\end{array}$ & $\begin{array}{l}I_{\text {sleep }} \\
(\mu \mathrm{A})\end{array}$ & $\begin{array}{c}\text { Bit } \\
\text { Rate } \\
\text { (Kb/S) }\end{array}$ \\
\hline ANS [19] & ANY900 & 802.15 .4 & ZigBee & 3.3 & 33 & 17 & $<6$ & 250 \\
\hline Microchip [20] & MRF24J40MA & 802.15 .4 & ZigBee & 3.3 & 23 & 19 & 2 & 250 \\
\hline Radiocrafts [21] & RC2400 & 802.15 .4 & ZigBee + 6lowpan & 3.3 & 34 & 24 & 1 & 250 \\
\hline Texas Inst. [22] & CC2430 & 802.15 .4 & ZigBee & 3.3 & 25 & 27 & 0.9 & 250 \\
\hline $\begin{array}{c}\text { Dresden } \\
\text { Elektronik [23] }\end{array}$ & $\begin{array}{l}\text { deRFmega128- } \\
22 \mathrm{M} 00\end{array}$ & 802.15 .4 & Zigbee + 6lowpan & 3.3 & 12.7 & 17.6 & $<1$ & 250 \\
\hline $\begin{array}{c}\text { Dresden } \\
\text { Elektronik [24] }\end{array}$ & $\begin{array}{l}\text { deRFsam3 } \\
\text { 23M10-2 }\end{array}$ & 802.15 .4 & ZigBee + 6lowpan & 3.3 & 42 & 40 & $<2$ & 250 \\
\hline
\end{tabular}

Figure 7 shows the consuming power in (dBm) for each 802.15.4 module. Obviously it's noted that deRFsam323M10-2 consume less power compared to other modules if we ignore the effect of maximum range between nodes. So we can candidate this module to compare IEEE 802.15.4 modules with other wireless communication techniques for IoT sensor networks.

\subsubsection{LPWA LoRaWAN Modules for Long Range Connectivity}

Semtech-LoRa, SigFox, Huawei/Neul, Qualcomm have put forward proposals to meet GERAN guidelines for narrowband IoT connectivity. Table 3 below gives a comparison between different LPWA LoRaWAN based modules in term of its power consumption.

Figure 8 shows the consumption power in $(\mathrm{dBm})$ for each LoRaWAN module for maximum transmitting power. Obviously its note that all modules almost consume same power if we take in consideration the effects of maximum range between nodes. We can candidates RN2483 module for applications of wide range connectivity between sensor nodes and central processing unit.

\subsection{Wireless Communication Protocols}

\subsubsection{Comparison between Different IoT Protocols}

Table 4 summarizes the main differences between Low Power Wi-Fi, ZigBee, 6LowPAN and LoRaWAN protocols. This table has been filled according to the data sheet for each successful candidate module. According to the data shown in Table 4, effect of distance between nodes on transmission power can be studied. Also, the effect of transmission time on power consumption can be studied.

\subsubsection{Effect of Distance between Nodes and Transmission Power}

In wireless transmissions, the relationship between the received power and the transmitted power as in 1 [3].

$$
D=\frac{1}{\frac{4 \pi}{\lambda} \sqrt{\frac{P_{r}}{P_{r} G_{r} G_{t}}}}
$$

where:

$D$ is the distance between two antennas.

$P_{r}$ is the power when the module receives data.

$P_{t}$ is the power when the module transmits data.

$G_{t}$ is the transmitting omni basic antenna gain.

$G_{r}$ is the receiving antenna gain.

$\lambda$ is wavelength.

When the frequency increases, the range decreases with constant transmission and receiving powers. In same time to increase range between sensor nodes, extra transmitted power needs. At this moment we cannot candidate a certain module for IoT applications in term of distance and power consumption due to the distance depends on the nature of application. 


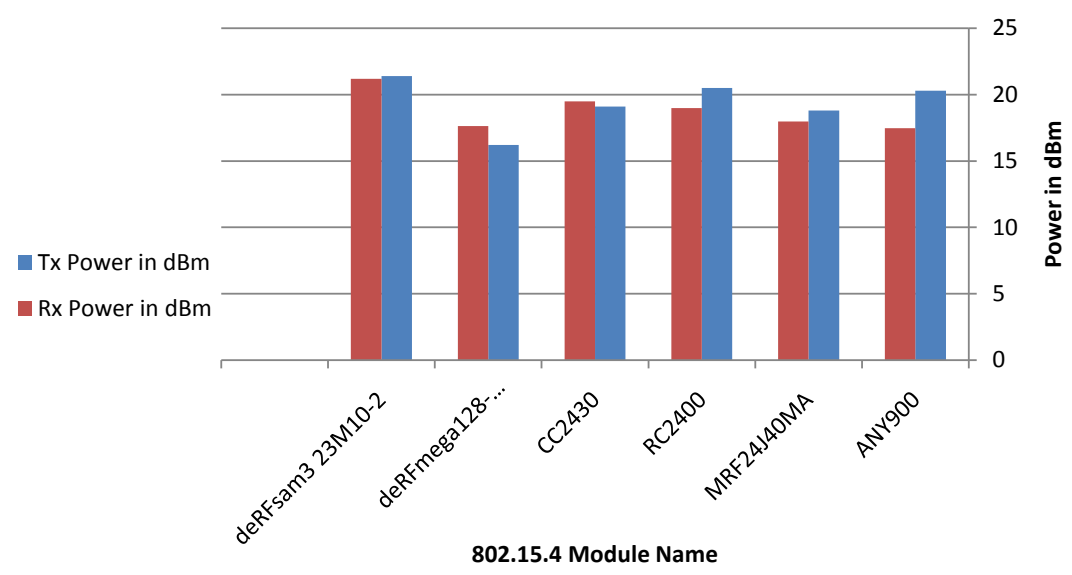

Figure 7. Power consumption in (dBm) for multiples 802.15.4 modules.

Table 3. Particular comparison for different LoRaWAN modules.

\begin{tabular}{|c|c|c|c|c|c|c|c|c|c|}
\hline Company & Module & $\begin{array}{c}\text { IEEE } \\
\text { Protocol }\end{array}$ & $\begin{array}{l}\text { Designed for } \\
\text { Network } \\
\text { Protocols }\end{array}$ & $\begin{array}{l}\mathrm{V}_{\mathrm{DD}} \\
\text { (Volt) }\end{array}$ & $\mathrm{I}_{\mathrm{TX}}(\mathrm{mA})$ & $\begin{array}{c}\mathrm{I}_{\mathrm{Rx}} \\
(\mathrm{mA})\end{array}$ & $\begin{array}{l}\mathrm{I}_{\text {sleep }} \\
(\mu \mathrm{A})\end{array}$ & $\begin{array}{l}\text { Bit Rate } \\
(\mathrm{Kb} / \mathrm{S})\end{array}$ & $\begin{array}{c}\text { Operation } \\
\text { Range } \\
\text { Km }\end{array}$ \\
\hline $\begin{array}{l}\text { Microchip } \\
\text { [25] }\end{array}$ & RN2483 & $\begin{array}{c}\text { Close Alignment } \\
\text { with IEEE } \\
802.15 .4\end{array}$ & $\begin{array}{l}\text { LoRaWANTM } \\
\text { Protocol Stack }\end{array}$ & 3.3 & $\begin{array}{c}38.9^{*} \\
32.9^{* *}\end{array}$ & 14.2 & 9.9 & $\begin{array}{c}5.468- \\
300\end{array}$ & $5-15 \mathrm{Km}$ \\
\hline $\begin{array}{l}\text { Multiteh } \\
\text { [26] }\end{array}$ & MTDOT-868-X1-SMA & $\begin{array}{c}\text { Close Alignment } \\
\text { with IEEE } \\
802.15 .4\end{array}$ & $\begin{array}{l}\text { LoRaWANTM } \\
\text { Protocol Stack }\end{array}$ & 3.3 & $26-41$ & 12 & 30.9 & $5.47-21.9$ & Up to $8 \mathrm{~km}$ \\
\hline $\begin{array}{l}\text { Nemeus } \\
\text { [27] }\end{array}$ & Nemeus-MM002 & $\begin{array}{c}\text { Close Alignment } \\
\text { with IEEE } \\
802.15 .4\end{array}$ & $\begin{array}{l}\text { LoRaWANTM } \\
\text { Protocol Stack }\end{array}$ & 3.3 & $20-39.5$ & 11.7 & $<2$ & $0.3-40$ & $\begin{array}{c}12 \mathrm{Km} \text { line } \\
\text { of sight }\end{array}$ \\
\hline
\end{tabular}

${ }^{*}$ Maximum transmitted power and 868MHz band. ${ }^{* *}$ This value for Maximum transmitted power and $433 \mathrm{MHz}$ band.

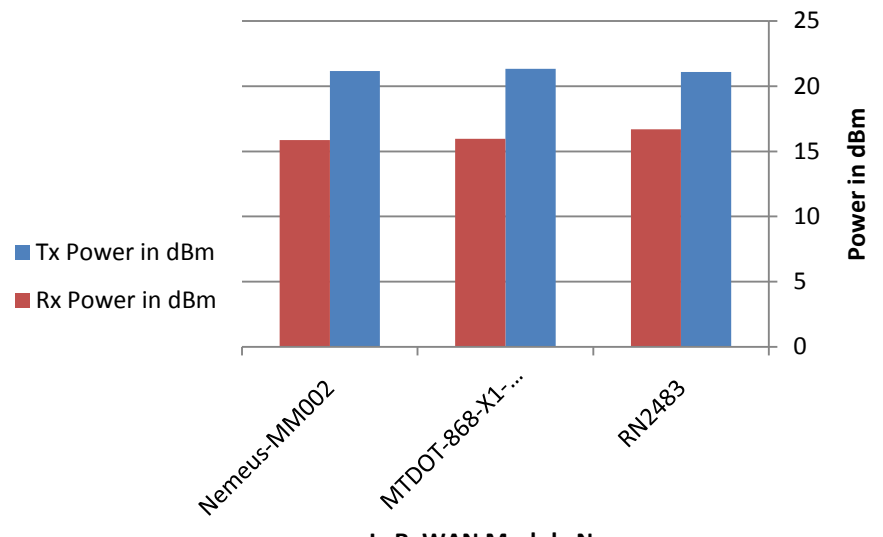

LoRaWAN Module Name

Figure 8. Power consumption in (dBm) for multiple LoRaWAN modules.

Table 4. Main differences between protocols that may be used in IoT applications.

\begin{tabular}{ccccc}
\hline Standard & Low Power Wi-Fi & ZigBee & 6LoWPAN & LoRaWAN \\
\hline IEEE spec. & $802.11 \mathrm{~b} / \mathrm{g} / \mathrm{h}$ & 802.15 .4 & 802.15 .4 & 802.15 .4 \\
Max Data Rate & $10 \mathrm{Mbps}$ & $250 \mathrm{Kbit} / \mathrm{s}$ & $250 \mathrm{Kbit} / \mathrm{s}$ & $5468 \mathrm{bps}$ LoRa Technology modulation \\
Nominal range & $70 \mathrm{~m}^{2}$ indoors and $225 \mathrm{~m}^{2}$ & $10-100 \mathrm{~m}$ & $25-50 \mathrm{~m}$ & $5-15 \mathrm{Km}$ \\
$\begin{array}{c}\text { Frequency band } \\
\text { (GHz) }\end{array}$ & Outdoors. & 2.4 & 2.4 & $433 / 868 \mathrm{MHz}$ \\
$\begin{array}{c}\text { Nominal TX } \\
\text { power }(\mathbf{m W})\end{array}$ & 19.95 & 52.22 & 2.23 & Adjustable with Max. Value $+14 \mathrm{dBm}$ \\
\hline
\end{tabular}


Table 5. Maximum data payload.

\begin{tabular}{cc}
\hline Protocol & Max. Data Payload (Byte) \\
\hline ZigBee [29] & 102 \\
6LoWPAN [30] & 102 \\
Low Power Wi-Fi [31] & 2312 \\
LoRaWAN [32] & 64 \\
\hline
\end{tabular}

\subsubsection{Transmission Time and Power Consumption}

The transmission time depends on the data rate, the message size, and the distance between two nodes. From Table 4, it is noted that the transmission time for the ZigBee and 6LoWPAN protocols is longer than the low power $\mathrm{Wi}-\mathrm{Fi}$, due to its low data rate $(250 \mathrm{~Kb} / \mathrm{s})$ and its long-range reasons. In long range connectivity, LoRaWAN requires more transmission time compared to small range connectivity protocols because its low rate data rate.

Compared to IEEE 802.15.4 with $250 \mathrm{~kb} / \mathrm{s}$ maximum data rate, IEEE $802.11 \mathrm{~b} / \mathrm{g}$ operates at much higher data rates ranging from $1 \mathrm{Mb} / \mathrm{s}$ to $54 \mathrm{Mb} / \mathrm{s}$. This allows Wi-Fi enabled sensors to spend very little time with actual transmission or reception. Operating at higher data rates also yields less power consumption since the higher the date rate is, the lower the receive/transmit energy per bit becomes. Hence, the impact of transmit and receive energy on battery lifetime becomes a secondary factor unless the Wi-Fi enabled sensor sends or receives large amounts of data [28].

The required transmission time is proportional to the data payload size and it is not proportional to the maximum data rate only [3]. So, another comparison between protocols must be introduced in terms of data payload size as shown in Table 5. Moreover the high radio data rate reduces frame transmission time, reducing the microcontroller unit idle time, resulting in overall energy consumption reduction. So, higher data rate and data payload resulting energy consumption reduction.

According to Table 5, its note that low power Wi-Fi protocol is preferred for IoT wireless sensor network and for short-range connectivity and in terms of its Max. data payload as compared with other protocols.

\section{Conclusions}

A study of wireless technologies for IoT applications in term of power consumption has been presented in this paper. It's seen that the choice of module for each protocol plays a vital role in battery life due to the difference of power consumption for each module/protocol. So, the evaluation of protocols with each other depends on the module used. For short range connectivity, deRFsam323M10-2 module form Dresden Elektronik is the candidate for IEEE 802.15.4 protocol and RTX41x series from RTX is the candidate for IEEE low power Wi-Fi protocols. For long range connectivity, LoRaWAN protocol is a good candidate because it is designed for IoT applications with low power consumption.

The maximum range for transmission and receiving depends on modules and protocols type. So, in sense of distance effect on power consumption, there is no certain module or protocol can be candidate for IoT applications, because the distance depends on the nature of application.

Data rate and payload of protocol affect directly on power consumption. High data rate and long data size of protocol lead to low power consumption. So, on the level of protocols for short-range connectivity low power Wi-Fi protocols is the best solution also on the level of modules.

\section{References}

[1] Luigi, A., Antonio, I. and Giacomo, M. (2010) The Internet of Things: A Survey. International Journal of Computer and Telecommunications Networking, 54, 2787-2805.

[2] Mats Andersson, CTO and Connect Blue (2014) Short-Range Low Power Wireless Devices and Internet of Things (IoT). Version 1.1. http://www.connectblue.com

[3] Saad, C. and Mostafa, B. (2014) Comparative Performance Analysis of Wireless Communication Protocols for Intelligent Sensors and Their Applications. International Journal of Advanced Computer Science and Applications, 5, 76-85. http://dx.doi.org/10.14569/IJACSA.2014.050413

[4] Institute of Electrical and Electronics Engineers, IEEE Std 802.15.4-2006. "Wireless Medium Access Control (MAC) 
and Physical Layer (PHY) Specifications for Low-Rate Wireless Personal Area Networks (WPANs).

[5] ZigBee Alliance (2006) ZigBee Specifications. Version 1.0 r13. http://www.zigbee.org/

[6] Perez, U.A. (2015) Low Power Wi-Fi: A Study on Power Consumption for Internet of Things. Master's Thesis, Facultat d'Informàtica de Barcelona (FIB), Universitat Politècnica de Catalunya (UPC), BarcelonaTech.

[7] Doukas, C. (2012) Building Internet of Things with the Arduino. Charalampos, Doukas.

[8] (2006) Ericsson White Paper. Cellular Networks for Massive IoT.

[9] (2014) Microchip Technology Inc., 2.4 GHz IEEE Std. 802.11 b/g Wireless LAN RN171 Module Specification Sheet.

[10] Colitti, W. (2011) State-of-the-Art: Communication, Technology, Interoperability. Version: 0.3, ISN—Interoperable Sensor Networks.

[11] Semtech Corporation Whitepaper (2015) LPWA Technologies-Unlock New IoT Market Potential. Machina Research.

[12] Rayal, F. (2015) Shaping Cellular IoT Connectivity_Emerging Technologies in Wide-Area Connectivity. Xona Partners Team. www.xonapartners.com

[13] Qualcomm Inc. (2015) QCA4004 Module Specifications Sheet.

[14] Gain Span Inc. (2011) GS1011M Low-Power Wireless System-on-Chip Wi-Fi Modules Data Sheet.

[15] G2 Microsystem Inc. (2008) G2M5477 Preliminary Data Sheet. Document Version 0.14a.

[16] Redpine Inc. (2012) RS9110-N-11-02 802.11bgn WLAN Module Data Sheet. Version 1.49.

[17] RTX Inc. RTX41xx Wi-Fi Modules. www.rtx.dk

[18] Toscano, E. and Lo Bello, L. (2012) Comparative Assessments of IEEE 802.15.4/ZigBee and 6LoWPAN for Low-Power Industrial WSNs in Realistic Scenarios. 9th IEEE International Workshop on Factory Communication Systems, Lemgo, 21-24 May 2012, 115-124. http://dx.doi.org/10.1109/wfcs.2012.6242553

[19] ANS Inc. (2011) ANY900 868/915MHz IEEE802.15.4 RF Module Specification Sheet.

[20] Microchip Technology Inc. (2008) MRF24J40MA Module Data Sheet.

[21] Radiocrafts Embedded Wireless Solutions (2009) RC2400/RC2400HP Modules Short Form Data Sheet.

[22] Chipcon Products from Texas Instruments (2006) CC2430 Preliminary Data Sheet.

[23] Dresden Elecktronik (2014) User Manual Radio Module deRFmega128-22M00. Document Version V1.4.1.

[24] Dresden Elecktronik (2013) Radio Module deRFsam3 23M10-2 Datasheet.

[25] Microchip Technology Inc. (2015) Low-Power Long Range LoRa ${ }^{\mathrm{TM}}$ Technology Transceiver RN2483 Module Specification Sheet.

[26] Multi-Tech Systems, Inc. (2015) MultiConnect mDot MTDOT Module Developer Guide.

[27] Nemeus Long Range Wireless Solution (2015) Nemeus-MM002 Module Datasheet.

[28] Tozlu, S., Senel, M., Mao, W. and Keshavarzain, A. (2012) Wi-Fi Enabled Sensors for Internet of Things: A Practical Approach. IEEE Communication Magazine, 50, 134-143. http://dx.doi.org/10.1109/MCOM.2012.6211498

[29] Burchfield, T.R., Venkatesan, S. and Weiner, D. (2007) Maximizing Throughput in ZigBee Wireless Networks through Analysis, Simulations and Implementations. Proceedings of the International Workshop on Localized Algorithms and Protocols for Wireless Sensor Networks, Santa Fe, 18-20 June 2007, 18-20.

[30] Montenegro, G., Kushalnagar, N., Hui, J. and Culler, D. (2007) Transmission of IPv6 Packets over IEEE 802.15.4 Networks. Network Working Group, Copyright (C) IETF Trust.

[31] Lee, J.-S., Su, Y.-W. and Shen, C.-C. (2007) A Comparative Study of Wireless Protocols: Bluetooth, UWB, ZigBee, and Wi-Fi. 33rd Annual Conference of the IEEE Industrial Electronics Society (IECON), Taipei, 5-8 November 2007, 46-51. http://dx.doi.org/10.1109/iecon.2007.4460126

[32] Sornin, N., Luis, M., Eirich, T., Kramp, T. and Hersent, O. (2015) LoRaWAN ${ }^{\mathrm{TM}}$ Specifications. LoRa ${ }^{\mathrm{TM}}$ Alliance. 